\title{
Heart rate within male crayfish: social interactions and effects of 5 -HT
}

\author{
Laura R. Listerman ${ }^{\text {a }}$, Jasson Deskins ${ }^{\text {a }}$, Haymo Bradacs ${ }^{\mathrm{b}}$, Robin L. Cooper ${ }^{\mathrm{a}, *}$ \\ a Thomas Hunt Morgan School of Biological Sciences and Center for Ecology Evolution and Behavior, University of Kentucky, \\ Lexington, KY 40506-0225, USA \\ ${ }^{\mathrm{b}}$ Institut für Zoologie der Universite Graz, Abt. für Neurobiologie, Graz, A-8010 Austria
}

Received 17 June 1999; received in revised form 16 November 1999; accepted 18 November 1999

\begin{abstract}
Behaviors, such as those that establish dominant and subordinate social status, are thought to be driven by various neuromodulators and hormones. In crustaceans, the level of serotonin (5-HT) in the hemolymph is correlated with degree of aggressiveness. The crustacean heart is neurogenic and is modulated by neural secretion of 5-HT in the hemolymph, which bathes the cardiac tissue. We discuss and present the results of measuring heart rate (HR) of crayfish during interactions, as an indication of their state of excitability. HR is the result of multiple influences: a cocktail of hormones and modulators. HR was monitored during the periods in which crayfish established aggressive and submissive social status, during sham injections, and following injections of various doses of 5-HT. Crayfish, during an interaction to establish social status, can increase HR. Both the aggressive and submissive crayfish can dampen their HR within seconds during a pause in the interaction, while still posturing in an aggressive or submissive state. Injections of 5-HT to obtain systemic levels of approximately $100 \mathrm{nM}-10 \mu \mathrm{M}$ increase HR substantially for hours. This suggests that aggressive interactions and the establishment of a dominant posture may not be related to large increases in the free concentrations of 5-HT within the circulating hemolymph, since a sustained HR is not observed in aggressive animals. Instead, the results may demonstrate that inhibitory cardiac regulation is present in the aggressors during interactions and that a regulator is possibly 5-HT. (C) 2000 Elsevier Science Inc. All rights reserved.
\end{abstract}

Keywords: Heart rate; Crayfish; Crustacean; Serotonin; Social status; Hormones; Neuromodulators; Interactions; Hemolymph

\section{Introduction}

In invertebrates, particularly crustaceans, biogenic amines have a role in modulating behaviors and physiological processes such as feeding, reproductive receptiveness, aggressive and submissive social status, as well as heart rate (HR). Studies using lobsters and crayfish have shown

\footnotetext{
* Corresponding author. Tel.: + 1-606-257-5950; fax: + 1606-257-1717.

E-mail address: rlcoop1@pop.uky.edu (R.L. Cooper)
}

that, depending on the levels of serotonin (5-HT) in the hemolymph, the animals can be induced to either display aggressive or submissive postures (Livingston et al., 1980). Interactions during battles for social dominance are prolonged if 5-HT is elevated (Huber et al., 1997a,b). Lobsters injected with 5-HT into their circulatory systems assume a dominant posture with their chelipeds spread out and raised, with the abdomen semi-flexed (HarrisWarrick and Kravitz, 1984). Such a posture of the chelipeds is termed a 'meral spread' and is presumed to be a visual social status signal. Injection of octopamine results in submissive behavior and 
appropriate tonic extension of the extremities with the chelipeds lowered (Harris-Warrick and Kravitz, 1984). These postural behaviors have been demonstrated in crayfish, where they determine social hierarchy (Bruski and Dunham, 1987). Hierarchical social status among members of a group is important for reproductive success and territorial claims. Interactions are used to establish dominance which sometimes leads to the death of the weaker one (Bruski and Dunham, 1987).

More recently, the social status influences on synaptic function have been addressed (Yeh et al., 1996). Two particular monoamines, 5-HT and octopamine, are released into the animal's hemolymph from neuro-secretory organs (Evans et al., 1976; Livingston et al., 1980). 5-HT affects motor nerve terminals, in general, by increasing transmitter release (Florey and Rathmayer, 1978; Fischer and Florey, 1982; Glusman and Kravitz, 1982), but the behavioral extension or flexion of extremities is thought to result from selective modification of CNS output (Livingston et al., 1980; Harris-Warrick and Kravitz, 1984). Due to experimental difficulties by inadvertently stressing the animals when taking samples of hemolymph to test 5-HT levels while the animals are behaving, direct measures have not yet been forthcoming that relate intrinsic levels of biogenic amines to behaviors.

The adult crustacean heart is neurogenic in that the basic heart beat and rhythm are determined by the neural output of the cardiac ganglion (Alexandrowicz, 1932; Yamagishi and Hirose, 1997; Yamagishi et al., 1997; Wilkens, 1999). The CNS exhibits inhibitory and acceleratory effects on the cardiac ganglion which regulates cardiac rhythm. As early as 1932, Alexandrowicz (Alexandrowicz, 1932) described the innervation to the cardiac complex and proposed that the pericardial organs represented neurohemal organs releasing substances acting on the heart (Alexandrowicz, 1953). The cardiac ganglia of various crustaceans is influenced by several sorts of neurohumoral inputs. These include neurohormones and the release of 5-HT into circulation by the pericardial organ and from other neuroendocrine structures (Grega and Sherman, 1975; Cooke and Sullivan, 1982; Wilkens and McMahon, 1992; Yazawa and Kuwasawa, 1992; McGaw et al., 1995; Wilkens, 1999). Since HR increases when exposed to 5-HT, we used HR as a potential measure of the intrinsic level of 5-HT in the animals when they are establishing aggressive and submissive social status, as well as during injections of various doses of 5-HT. Monitoring HR provides a measure of the intrinsic state (excitability level) of the animal that is not exhibiting behavioral movements to an observer, even though the animal is very agitated. HR may serve as a good bio-index to measure levels of circulating biogenic amines since, experimentally, it is altered in a concentration-dependent manner. In short, 5-HT release may serve as an equivalent to epinephrine released from the sympathetic nervous system in vertebrates under comparable behavioral conditions.

The purpose of our study was to assess the HR of crayfish during social interactions as an index of their state of excitability. In addition we set out to determine if a relationship exists between the degree of alteration and duration of HR in comparison with 5-HT levels, that were increased by injection into the circulatory system of the crayfish.

Portions of these data have previously been presented in abstract form (Doshi et al., 1999; Listerman et al., 1999).

\section{Methods}

\subsection{Animals}

Procambarus clarkii (6-10 cm body length) were obtained from a commercial supplier, Atchafalaya Biological Supply Co. (Raceland, LA). The animals were housed in an aquatic facility within our regulated-temperature laboratory $\left(13-16^{\circ} \mathrm{C}\right)$. They were kept in individual tanks and fed fish food pellets weekly until the time of experimentation. During experimentation, food was readily available to the animals. Only male crayfish in their intermolt stage were used for experimentation.

\subsection{Recording procedures}

To obtain electrocardiograms (ECGs), two insulated iridium/platinum wires (diameter 0.005 inches and with the coating 0.008 inches; A-M Systems, Carlsburg, WA) were placed under the dorsal carapace directly over the heart (Fig. 1). Wires were inserted through holes drilled in the carapace and cemented in place with instant adhe- 
sive (Eastman, 5-min drying epoxy). These two wires were placed to span the heart in a rostralcaudal arrangement to insure an accurate impedance measure during each contraction. As with previous investigators, we found that prolonged handling stresses the animals and alters the physiological measurements for a time duration of $24 \mathrm{~h}$ to 3 days (Wilkens et al., 1985).

Initial studies were conducted using an extracellular P-15 amplifier (Grass Instruments). The data revealed that ECGs were being recorded along with electromyograms (EMGs) of the muscles that parallel the heart on both sides. HR was separable from EMG activity, but this was a long and time-consuming process. Therefore, an impedance detector (UFI, model 2991) was used, which allowed HR to be monitored as a measure of dynamic resistance. These signals were recorded on a VHS tape (Vetter, 400) and on-line to a PowerMac 9500 via a MacLab/4s interface (AD Instruments). All events were measured and calibrated with the MacLab Chart software version 3.5.6 (AD Instruments, Australia) with an acquisition rate set at $10 \mathrm{kHz}$ for EMGs and at 4 $\mathrm{kHz}$ for ECGs. Calibration pulses were provided by the P-15 amplifier (Grass Instruments). The typical recording obtained with the P-15 amplifier over a 5-s period is shown in Fig. 2A. The large deflections represent heartbeat. The higher-frequency, small-amplitude spikes represent muscle

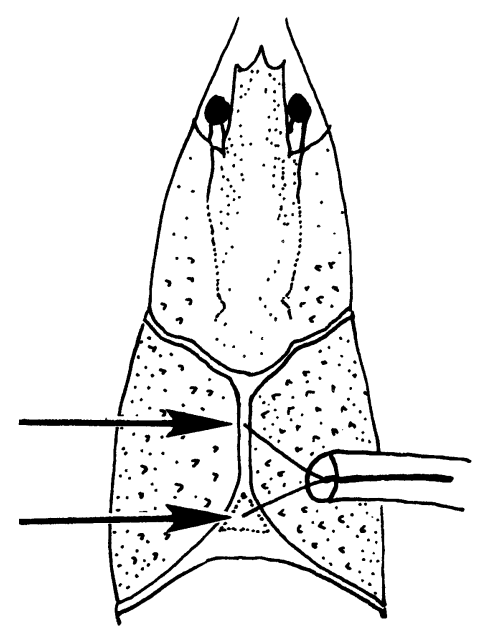

Fig. 1. The dorsal surface of a crayfish thorax showing the placement of the recording leads (arrows) to obtain EMGs and ECGs. activity, presumably from the lateral muscles flanking the heart. A frequency plot of the raw trace shows the muscle potential for the lateral muscles (Fig. 2B). For ease in counting each heart rate, a smoothing function was applied to the data set. If 100 points were smoothed (i.e. averaged) the resultant trace depicted only the heartbeats (Fig. 2C). This procedure was especially necessary when the animals were moving because the frequency of activity of the EMG was so high it masked the heartbeats. Alternatively, impedance measures do not monitor the high frequency EMG activity, so only the slow events of heartbeats were observed which allowed an easy measure of heart rate (Fig. 2D).

The heart rates were determined by direct counts of each beat over 10-s intervals and then converted to beats per $\min (\mathrm{BPM})$. The time between individual beats was used for instantaneous measures of HR. EMG activities from the lateral muscles paralleling the heart were analyzed by the amount of instantaneous frequency between events.

\subsection{Behavior}

Observational studies were made immediately following placement of the recording leads. This allowed us to ascertain if the conditions were suitable to conduct the visual interaction studies among con-specific partners. The partners were placed in a divided water-filled tank a few days prior to interaction. Since all recordings of behavior and electrophysiological responses displayed on the oscilloscope were captured together on video, the behaviors could be precisely sequenced with the ECG recordings.

\subsection{5-HT injections}

Observational studies were also made on the effects of injecting different doses of 5-HT into the hemolymph of the crayfish. Sham experiments were conducted in order to account for excitation of the HR caused by the handling and injection of the animals. Systemic levels of 5-HT were in calculated concentrations of low $(100 \mathrm{nM})$, medium $(1 \mu \mathrm{M})$, and high concentration $(10 \mu \mathrm{M})$. The amount of hemolymph was estimated on the basis of animal weight assuming that about 30\% of an animal's weight is hemolymph (Gleeson and 

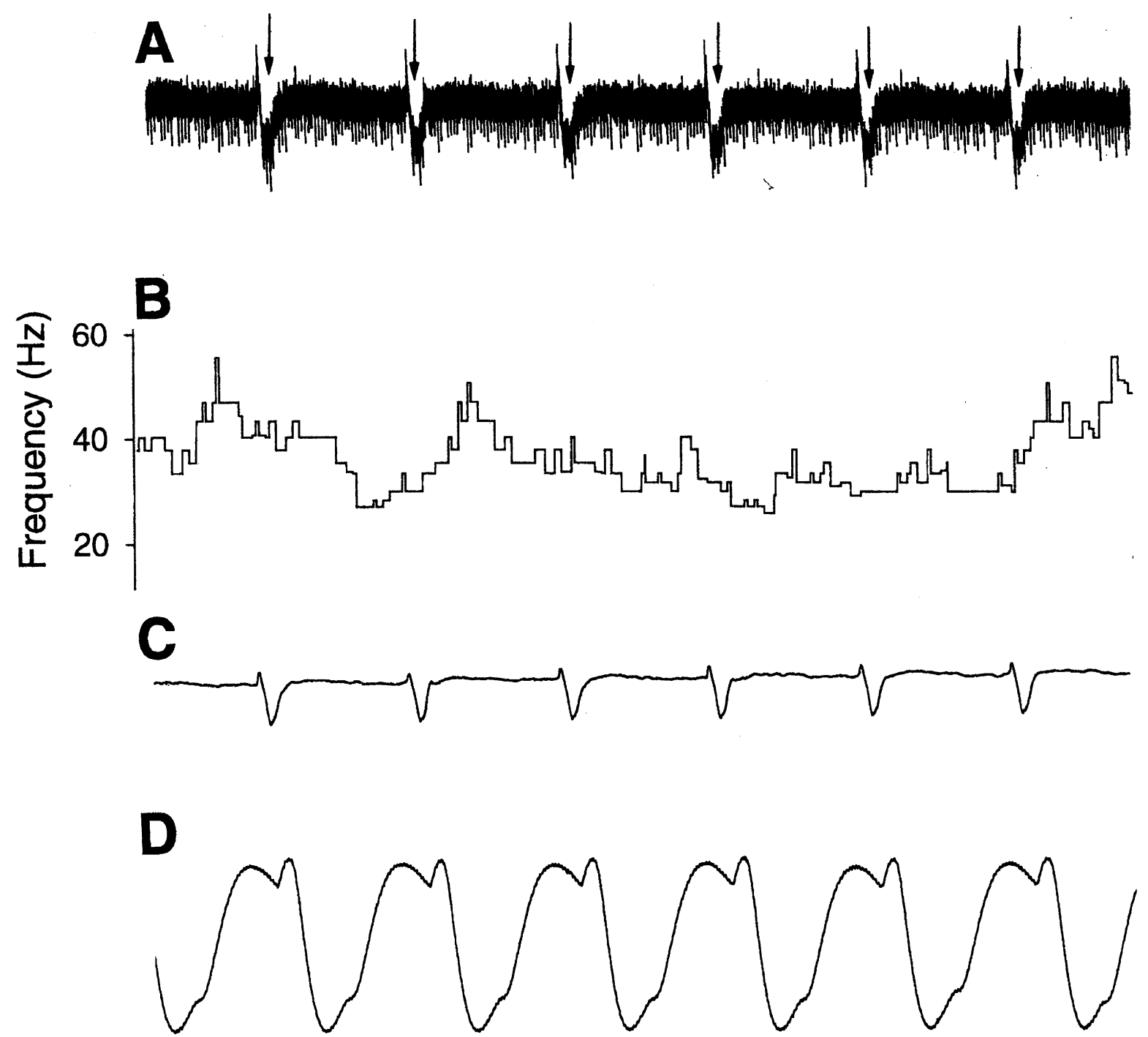

Fig. 2. (A) Both EMG and ECG activity are able to be simultaneously recorded with an amplifier (Grass, P-15) that measures both fast and slow transients. The frequency plot (B) is a running average of each spike shown in trace A. (C) Smoothing the raw trace with a function that averages every 150 points, allows a clear record of the slow ECG activity. Each arrow indicates a single contraction of the heart. (D) The use of an impedance amplifier provides a very clear record of the heart rate. All traces are $10 \mathrm{~s}$ in duration.

Zubkoff, 1977; Guirguis and Wilkens, 1995). The total volume was established for the appropriate volume of stock $(10 \mu \mathrm{M}) 5$-HT to be injected.5HT was diluted in physiological saline (Cooper and Ruffner, 1998) to a range of $200 \mu \mathrm{l}$ for the total injection volume. All injections were made through the ventral articulating membrane in the second abdominal segment. Since the animals have an open circulatory system, the 5-HT is carried toward the heart where it bathes the cardiac ganglion and muscle. Experiments were carried out using several animals for each concentration of 5-HT.

\section{Results}

\subsection{HR response during defense posturing and social interactions}

HR was recorded each day following placement of the recording wires for a 20 -min time period. An average HR was calculated for each day from an hour of observation time. The stress of handling and restraining the crayfish in order to glue the recording leads on the animal induced an elevated HR lasting approximately 2 days 
(mean \pm S.E.M.: Day $1, H R=112 \pm 1.46$ BPM; Day $2, \mathrm{HR}=110 \pm 1.56 \mathrm{BPM})$. Usually by the third day, the HR stabilized and remained at a basal rate for the subsequent days when the animal was sedentary (Day 3, HR $=85 \pm 1.27 \mathrm{BPM}$; Day 4 , HR $=84.8 \pm 1.07$ BPM). These numbers represent the average HR per day for one crayfish. All other crayfish showed the same trend in decreasing HR for 3 days following placement of wires. Therefore, all interactions and injections took place on day three.

A defense posture, or meral spread, can be induced in crayfish by an experimenter waving their hand approximately $60 \mathrm{~cm}$ overhead, casting a shadow over the animal's eyes (Fig. 3A). This posture is not used exclusively for social interactions. It is also a defense mechanism, a stance an

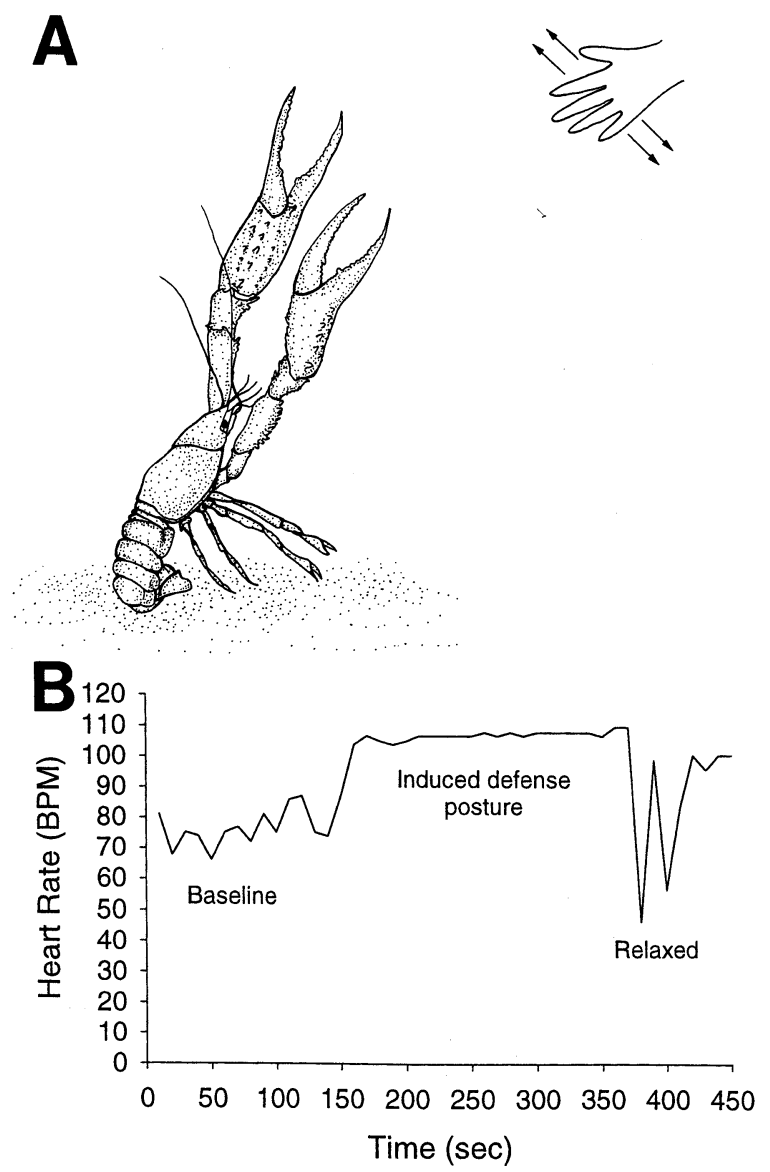

Fig. 3. (A) A defense posture can readily be induced in these sighted crayfish by providing a moving shadow across their eyes by a waving hand. The rapid response of a meral spread and tail flexion coincides with an increase in heart rate. (B) The elevated heart rate lasts for only a few minutes in the absence of the stimulation. animal assumes when threatened either by another crayfish or any type of visual motion it detects (Bethe, 1897; Wiersma, 1961; Larimer and Tindel, 1966). The HR always showed an increase after a short time $(<1 \mathrm{~min})$ with such a visual stimulus and associated posturing. The rate returned to baseline, in most cases, within 5 min after the disturbance (Fig. 3B).

For the interaction studies, after a baseline HR was recorded, the barrier separating crayfish was removed while still monitoring HR. The interactions were allowed to proceed for at least $20 \mathrm{~min}$ before the animals were separated, so as to stop the interaction before the animals injured or killed each other. The HR (BPM) was plotted for one representative crayfish during the entire duration of an interaction to demonstrate the fluctuation in HR during particular behavioral movements (Fig. 4). In three of the recordings, the EMG activity of lateral muscles along with cardiac beats were recorded (P-15 amplifier). The spike frequency of the EMG activity showed a correlation to HR during the social behaviors (Table 1). The typical behaviors observed during this type of experimental design are described next (Fig. 4) and the HR values are listed in Table 1.

As the barrier between the two crayfish is removed, they begin exploring new areas of the tank. This always results in an increased HR over baseline from when the animals were sedentary. The cue that a visual interaction had begun between the crayfish is that, when facing each other, HR gradually increases as does the EMG activity, even though the crayfish are remaining still. Once one crayfish has realized that another is present, it becomes likely that they will physically interact and that either one or both will assume the defense posture. As they begin to anticipate the upcoming interaction and start to touch each other with their antennae or claws, HR may increase more substantially. With the onset of physical contact, HR greatly increases during the rapid intense movements. In some cases, this physical contact may not be very interactive (i.e. the animals are just beginning to push one another), yet a tremendous increase in $\mathrm{HR}$ can occur. As the interaction becomes physically intense and the animals enter the full battle stage, HR can take a dramatic jump upwards. At any time during this interaction, the crayfish may pause in the battle, and curiously enough, their HR can dramatically decrease even though they still maintain a defensive or aggres- 
Table 1

EMG and/or ECG activity monitored along with characteristic behaviors as a measure of an animal's internal status during social interactions ${ }^{\mathrm{a}}$

\begin{tabular}{|c|c|c|c|c|c|c|c|c|c|c|c|}
\hline \multirow[b]{2}{*}{ Aggressive } & \multirow[b]{2}{*}{$\lambda(\mathrm{Hz})$} & \multirow{2}{*}{$\begin{array}{l}\text { Baseline } \\
20\end{array}$} & \multicolumn{2}{|c|}{ Anticipation: visual only } & \multicolumn{2}{|c|}{ Antennae touching } & \multicolumn{2}{|c|}{ Pushing } & \multicolumn{2}{|c|}{ Full battle } & \multirow{2}{*}{$\begin{array}{l}\text { Separated back to baseline } \\
30\end{array}$} \\
\hline & & & 30 & $(50)$ & 50 & $(150)$ & 60 & $(200)$ & 80 & $(300)$ & \\
\hline & HR (BPM) & 42 & 60 & $(42.9)$ & 84 & $(100)$ & 102 & $(142.9)$ & 114 & (171.4) & 48 \\
\hline \multirow[t]{2}{*}{ Submissive } & $\lambda(\mathrm{Hz})$ & 30 & 30 & (0) & 40 & (33.3) & 40 & $(33.3)$ & 70 & $(133.3)$ & 30 \\
\hline & HR (BPM) & 78 & 84 & $(7.7)$ & 96 & $(23.1)$ & 72 & $(7.7)$ & 96 & $(23.1)$ & 66 \\
\hline \multirow[t]{2}{*}{ Aggressive } & $\lambda(\mathrm{Hz})$ & 20 & 30 & (50) & 35 & $(75)$ & 45 & $(125)$ & 50 & $(150)$ & 10 \\
\hline & HR (BPM) & 48 & 84 & $(75)$ & 96 & $(100)$ & 102 & (112.5) & 96 & $(100)$ & 60 \\
\hline Submissive & HR (BPM) & 90 & 78 & $(13.3)$ & 78 & (13.3) & 90 & $(0)$ & 114 & $(26.7)$ & 72 \\
\hline Aggressive & HR (BPM) & 66 & 78 & (18.2) & 84 & (27.3) & 120 & (81.8) & 150 & (127.7) & 60 \\
\hline Submissive & HR (BPM) & 72 & 72 & (0) & 96 & (33.3) & 110 & $(52.8)$ & 110 & $(52.7)$ & 78 \\
\hline $\begin{array}{l}\text { Mean (\% in- } \\
\text { crease) }\end{array}$ & & & & (26.18) & & $(49.5)$ & & $(66.28)$ & & (83.6) & \\
\hline S.E.M. & & & & (11.43) & & (16.19) & & $(23.28)$ & & (24.34) & \\
\hline
\end{tabular}

a Percentage increase in parentheses. Six behaviors that are readily distinguishable were used among three pairs of crayfish. The social status was determined from the interaction used to obtain the data presented, but also from subsequent interactions. Interactions took from 20 to 40 min before a full battle would take place, at which time they were separated back to individual holding tanks. From the EMG records the average frequency $(\lambda ; \mathrm{Hz})$ was obtained from every 51 events. After smoothing of the traces as illustrated in Fig. 2 , the heart rate (HR) in beats per min (BPM) was directly counted to obtain an average value during each given behavior. Note that when HR increased, EMG activity of the lateral muscles and the heart increased as well. The frequency responses were collected only for the first three crayfish presented in the table. 


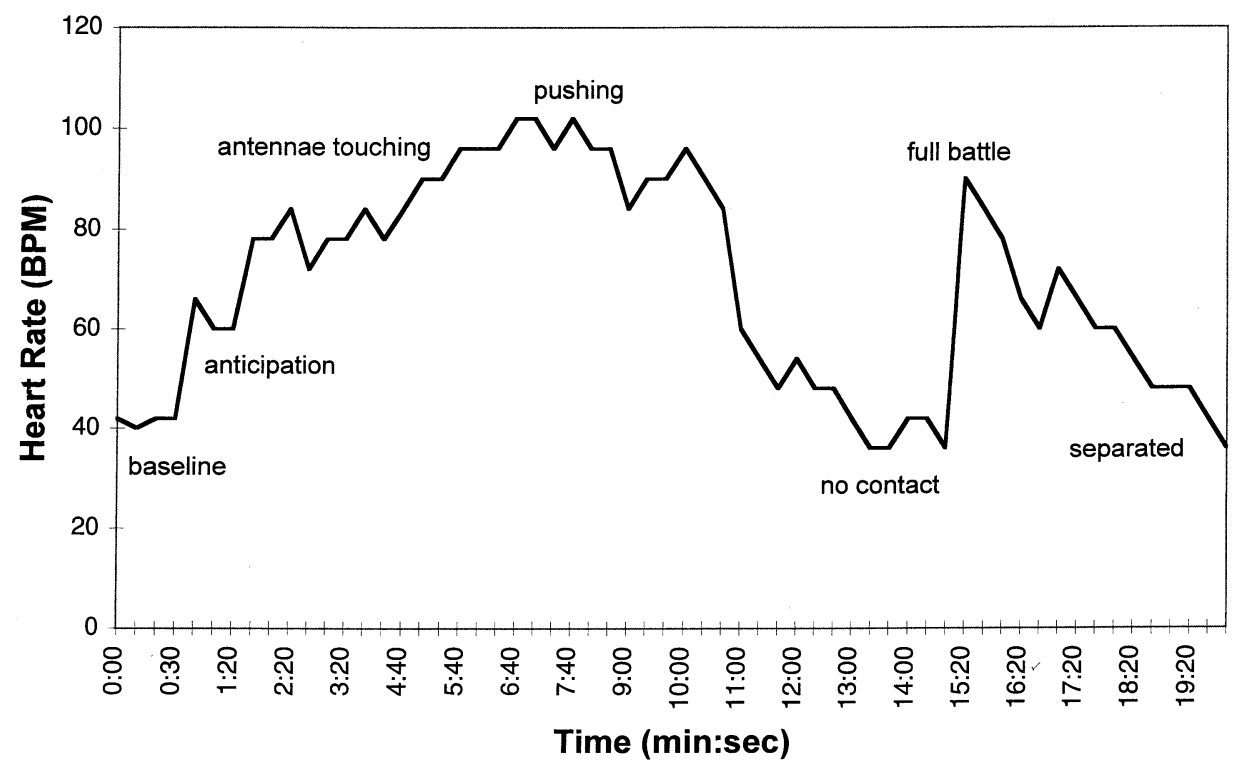

Fig. 4. The heart rate before and during an interaction in one of the pairs demonstrates the correlation of heart rate with each of the behaviors associated with a 20 -min interaction. The baseline is obtained prior to the divider in the tank being removed when the animal is not aware of the other's presence. Upon the presence of the opponent, producing a meral spread, the recorded crayfish's response is to increase heart rate: anticipation. When the animals become close enough and touch each others antennae, heart rate continues to increase: antennae touching. When an engagement of the chelae occurs to push each other, the heart rate is high during the entire physical interaction: pushing. Both crayfish take a break, but are still in close proximity to each other, heart rate declines rapidly: no contact. During a short bout of a full-blown battle which includes jabbing action of the chelae of both pairs and strong clasping of the chelae, heart rate quickly soars up (full battle). When the animals pause and slowly the other opponent backs away, the heart rate decreases at which point the animals are separated and heart rate regains its basal rate prior to the pairing: separated.

sive posture. Over time, one crayfish may take a submissive posture by keeping still with the chelipeds in a lowered position.

The heart rate in the submissive animal increases upon the first visual contact and, subsequently after dominance has already been established among the pair, when the dominant partner bluffs with a meral spread. Even if the submissive crayfish remains with its chelipeds in a down position and attempts to avoid physical engagement, its HR is higher than the basal rate.

In nearly all cases, as shown in Table 1, EMG frequency increases concomitant with the rise in HR, although the percent changes may be substantially higher for the EMG activity.

An additional representative experiment of HR (BPM) during the entire duration of an interaction is shown, including both crayfish and depicting only the ECG activity (Fig. 5). From subsequent interactions and behavioral observations, it is readily determined which one of the pair is the dominant or submissive individual. Notice that even during a fight, the submissive animal can lower its HR, although upon initiating a full battle, HR dramatically increases. When the battle is over (at the 15-min point in Fig. 5), both individuals can drop their HR to levels lower than before the physical tank divider was removed to initiate the social interaction. Table 1 is a composite of interaction studies in which HR and EMG measures were taken simultaneously by use of a P-15 amplifier. In general, the crayfish increase their HR when they first see each other and anticipate a battle. HR increases dramatically during a battle, but decreases quickly after the battle.

\subsection{The role of 5-HT injections on $H R$}

To determine the effect 5-HT has on HR, various amounts of 5-HT were injected into the crayfish to produce approximate concentrations of 5-HT within the circulating hemolymph. Sham injections were administered to several animals in order to compare HR with those that were injected with 5-HT (Fig. 6). The entire injection procedure, from picking up the animals to return- 
ing them to the tank, lasted $30 \mathrm{~s}$. This handling usually resulted in a 1-h elevation of HR. A low concentration of 5-HT $(100 \mathrm{nM})$ produced a tachycardia lasting about $5 \mathrm{~h}$ (Fig. 7). A medium concentration of 5-HT $(1 \mu \mathrm{M})$ induced an extended tachycardia. Subsequently higher concentrations, induced in individual crayfish, resulted in very prolonged tachycardia up to $10.5 \mathrm{~h}$. Although statistical treatment of the data is difficult due to the extreme variation of baseline HR among different animals, all experiments showed the same trend: the duration of increased HR following an injection is concentration-dependent (Table 2).

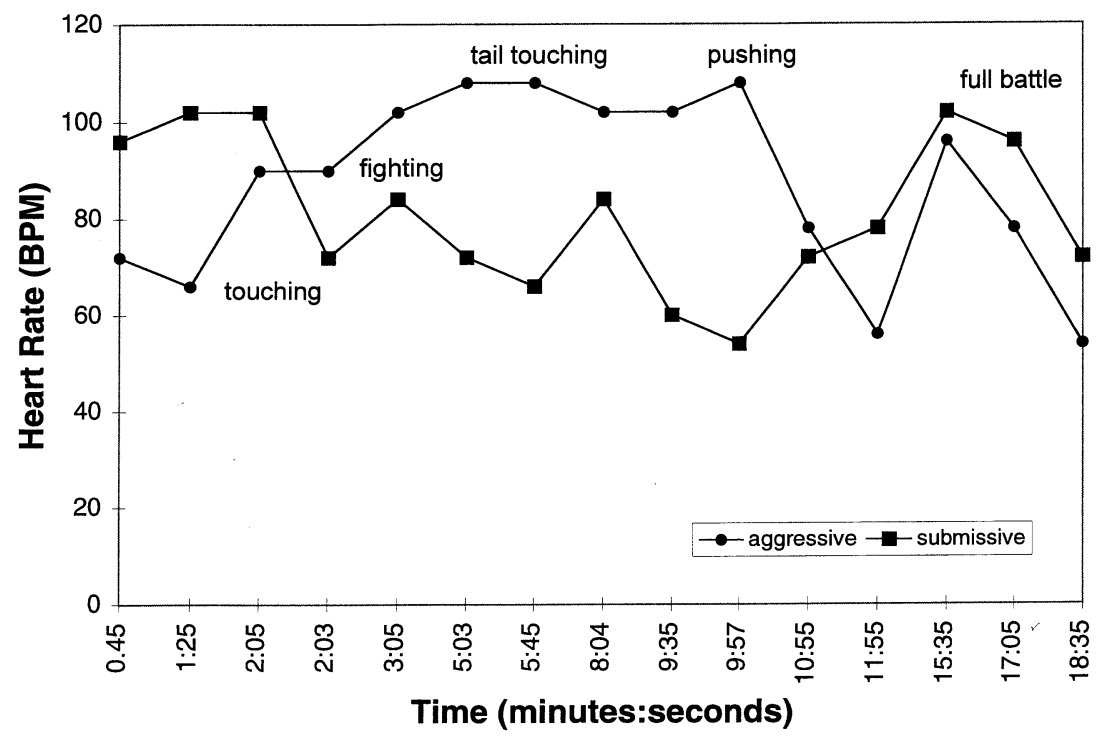

Fig. 5. ECG activity for an aggressive and submissive crayfish during the initial pairing in which to establish a social hierarchy. The observed behaviors are indicated which allows direct correlation to the behaviors displayed. The social status of being the aggressive or submissive individual does not correlate with basal levels of heart rate nor to the levels of heart rates obtained throughout the social interaction.

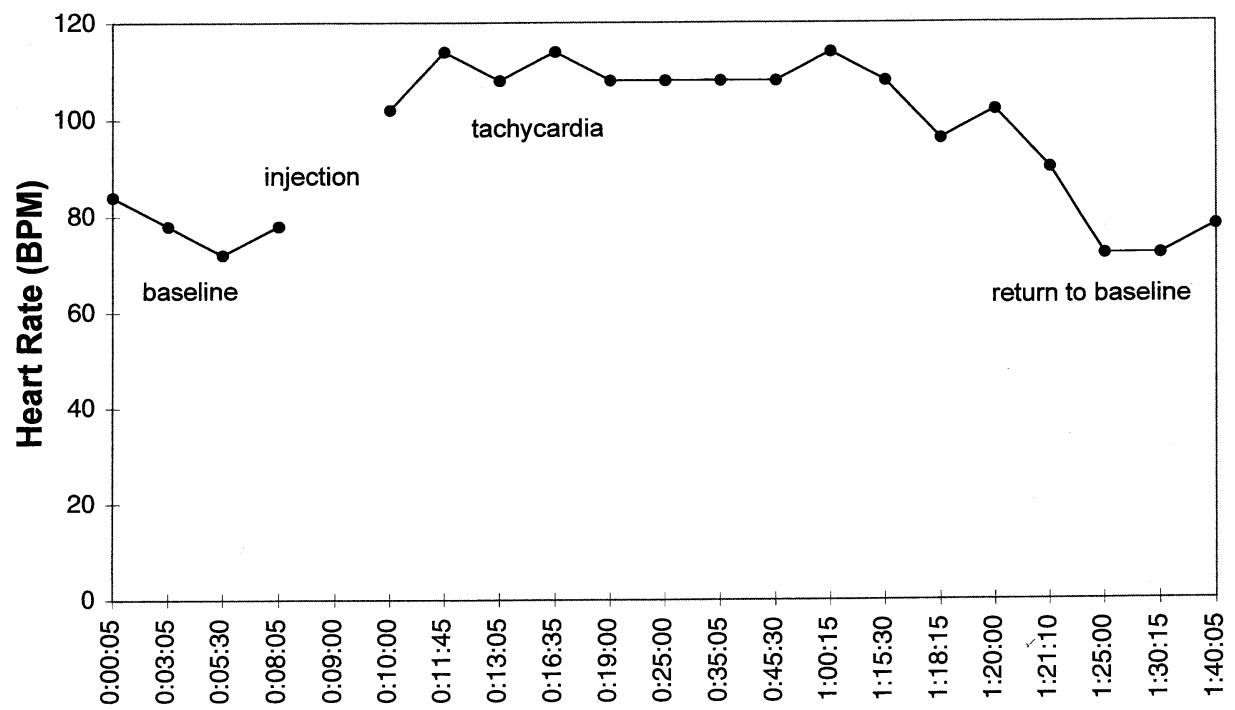

Time (h:m:s)

Fig. 6. Sham injections of the carrier solution used in 5-HT injection studies reveal that heart rate does increase due to the rapid injection and handling. The total handling time is less then $1 \mathrm{~min}$ but heart rate remains high for approximately $1 \mathrm{~h}$ (see also Table 2 ). 


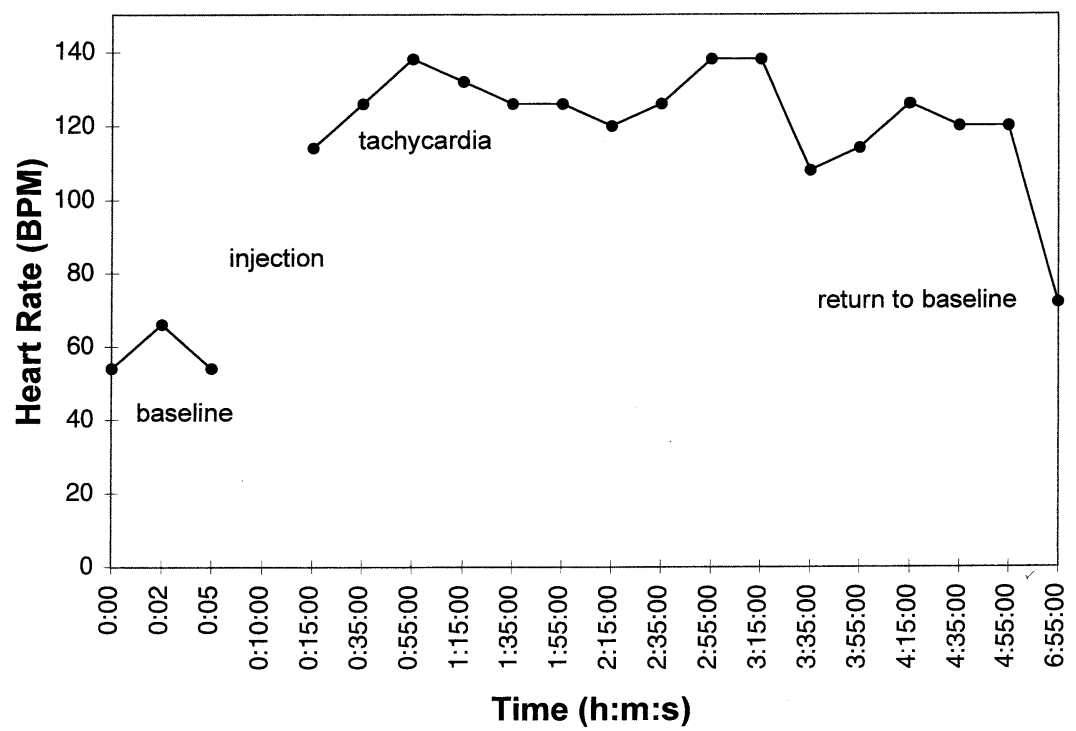

Fig. 7. An injection of 5-HT to a calculated circulating concentration of $100 \mathrm{nM}$ results in a sustained increase in heart rate for at least $5 \mathrm{~h}$, five times longer than observed for sham injections.

Table 2

Measures of heart rate (HR) in beats per min (BPM) for individual crayfish that were either handled or injected to obtain various calculated hemolymph levels of $5-\mathrm{HT}^{\mathrm{a}}$

\begin{tabular}{|c|c|c|c|c|c|c|c|c|c|c|}
\hline & \multirow[t]{2}{*}{ Prep. } & \multirow[t]{2}{*}{ Baseline HR } & \multicolumn{7}{|c|}{ Average heart rate after injection (BPM) } & \multirow[t]{2}{*}{ Time to return to baseline } \\
\hline & & & $30 \mathrm{~min}$ & $1 \mathrm{~h}$ & $2 \mathrm{~h}$ & $3 \mathrm{~h}$ & $4 \mathrm{~h}$ & $5 \mathrm{~h}$ & $6 \mathrm{~h}$ & \\
\hline $\begin{array}{l}\text { No injection; handling } \\
\text { only }\end{array}$ & 1 & 42 & 114 & 48 & & & & & & \\
\hline Sham injection & $\begin{array}{l}1 \\
2\end{array}$ & $\begin{array}{l}36 \\
78\end{array}$ & $\begin{array}{r}48 \\
108\end{array}$ & $\begin{array}{r}48 \\
114\end{array}$ & $\begin{array}{l}36 \\
72\end{array}$ & & & & & \\
\hline Low dose $(100 \mathrm{nM})$ & $\begin{array}{l}1 \\
2 \\
3 \\
4 \\
5\end{array}$ & $\begin{array}{l}60 \\
48 \\
66 \\
60 \\
60\end{array}$ & $\begin{array}{r}108 \\
114 \\
120 \\
84 \\
132\end{array}$ & $\begin{array}{r}102 \\
84 \\
120 \\
78 \\
144\end{array}$ & $\begin{array}{r}78 \\
120 \\
60 \\
126\end{array}$ & $\begin{array}{r}78 \\
66 \\
138\end{array}$ & $\begin{array}{r}78 \\
78 \\
120\end{array}$ & $\begin{array}{r}72 \\
84 \\
120\end{array}$ & $\begin{array}{r}66 \\
78 \\
102\end{array}$ & 66 (7 h) \\
\hline Medium dose $(1 \mu \mathrm{M})$ & $\begin{array}{l}1 \\
2 \\
3 \\
4 \\
5\end{array}$ & $\begin{array}{l}60 \\
30 \\
66 \\
42 \\
42\end{array}$ & $\begin{array}{r}126 \\
96 \\
150 \\
120 \\
120\end{array}$ & $\begin{array}{r}120 \\
102 \\
150 \\
102 \\
78\end{array}$ & $\begin{array}{r}114 \\
66 \\
150 \\
90 \\
60\end{array}$ & $\begin{array}{l}84 \\
66 \\
60\end{array}$ & $\begin{array}{l}84 \\
66 \\
72\end{array}$ & $\begin{array}{l}78 \\
60 \\
60\end{array}$ & $\begin{array}{l}54 \\
54 \\
60\end{array}$ & $48(10.5 \mathrm{~h})$ \\
\hline High dose $(10 \mu \mathrm{M})$ & $\begin{array}{l}1 \\
2 \\
3 \\
4 \\
5\end{array}$ & $\begin{array}{l}60 \\
60 \\
42 \\
42 \\
72\end{array}$ & $\begin{array}{l}114 \\
120 \\
150 \\
120 \\
138\end{array}$ & $\begin{array}{l}126 \\
120 \\
150 \\
120 \\
120\end{array}$ & $\begin{array}{r}48 \\
84 \\
102 \\
114 \\
126\end{array}$ & $\begin{array}{r}78 \\
114 \\
120\end{array}$ & $\begin{array}{r}72 \\
108 \\
108\end{array}$ & $\begin{array}{l}66 \\
90 \\
96\end{array}$ & $\begin{array}{l}60 \\
84 \\
78\end{array}$ & $\begin{array}{l}48(10.5 \mathrm{~h}) \\
42(9.5 \mathrm{~h}) \\
72(7 \mathrm{~h})\end{array}$ \\
\hline
\end{tabular}

a Picking up an animal and setting it back down resulted in a increased HR for about 30 min, whereas injecting a sham volume of saline without 5-HT resulted in an elevated HR for at least $1 \mathrm{~h}$. The low level (100 nM) 5-HT induced an elevated HR for about $3 \mathrm{~h}$ in two of the cases, but in one case HR remained high for up to $7 \mathrm{~h}$. The higher levels ( 1 and $10 \mu \mathrm{M})$ of induced 5-HT increased HR to higher levels for a more prolonged time in a concentration-dependent manner. 


\section{Discussion}

This study reports a novel measure of the intrinsic state in socially interacting crustaceans by the use of monitoring heart rate (HR). Previous reports on observational studies in interacting lobsters or crayfish have provided insight as to how social hierarchy can be established among these animals. These reports contain suggestive evidence that circulating levels of biogenic amines may have a role in shaping the social structure. As far as we are aware, no reports have appeared previously in which physiological measures have been acquired in a pair of interacting crustaceans while they are establishing social status or while the researcher is taking direct measures of biogenic amines. Physiological measures are routinely obtained in behavioral studies involving mammals, but such measures are more difficult to obtain in small aquatic crustaceans. Nevertheless, with the appropriate insulated recording leads, physiological measures are readily available.

The significance of this work is in the ability to obtain physiological measures of HR in crayfish prior to, during, and after social interactions of both the aggressive and submissive individuals. In addition, we performed correlative measures of HR and induced systemic levels of 5-HT by injection into the hemolymph to determine the effects of such systemic concentrations on HR. We do not precisely know the endogenous levels of release, or how the injected 5-HT is handled in relation to non-specific and specific binding within the hemolymph during the injection studies. Yet, this approach is currently the easiest and quickest way of altering the levels of 5-HT while monitoring HR.

The cumulative actions of 5-HT in decapods (i.e. crayfish, crabs, and lobsters) appear to 'tuneup' neural responses systemically for both inhibitory and excitatory neurons. The motor nerve terminals in the periphery and on abdominal muscles, enhance the ability to release more neurotransmitter (Florey and Rathmayer, 1978; Fischer and Florey, 1982; Glusman and Kravitz, 1982; Crider and Cooper, 1990; Delaney et al., 1991; Vyshedskiy et al., 1998; Worden, 1998). The visual system is altered in its sensitivity by migrating pigments (Aréchiga et al., 1990) which may explain phototaxic behaviors (McPhee and Wilkens, 1989). Primary proprioceptors in the abdomen increase their sensitivity (Pasztor and
Bush, 1987; Pasztor and MacMillan, 1990; Li et al., 1997), and ventilatory rate as well as HR are enhanced. Also, there is a direct action on skeletal muscle (Kravitz et al., 1980) and blood vessels for directing blood flow (McMahon, 1992; McGaw et al., 1995). The few excitatory and inhibitory motor neuron cell bodies examined within the ventral nerve cord (i.e. CNS) show selective effects of 5-HT in altering threshold levels of activation (Harris-Warrick and Kravitz, 1984). Thus, the directed actions on command neurons are likely the ones to dominate in regulating activity to the periphery, controlling the observed behaviors. The multiple actions and selective effects within the CNS and periphery appear to be analogous to aspects of sympathetic responses in mammals (Lefkowitz et al., 1990; McMahon, 1995).

The selective actions of 5-HT on the cardiac rate in crustaceans have been shown in both in situ and in vivo preparations (Florey and Rathmayer, 1978; Wilkens and Walker, 1992; Wilkens and Mercier, 1993; Wilkens, 1995, 1999) even after elimination of central neural control (HarrisWarrick and Kravitz, 1984). These suggest a role for systemic 5-HT in directly modulating the heart, although the largest changes in HR occur with intact innervation (Harris-Warrick and Kravitz, 1984). If an endogenous release of 5-HT occurs during the establishment and maintenance of social dominance, similar observations in the onset, duration, and degree of effect on the HR would be anticipated during normal interactions between crayfish (as observed by direct application of 5-HT in either in situ or in vivo preparations).

We have shown that $\mathrm{HR}$ is rapidly increased when isolated crayfish take a defense posture induced by a rapid, 5-s visual stimulus. The increase in HR only lasts a few minutes at most, before HR returns to basal levels. With paired crayfish, the visual mural display of one crayfish in close proximity induced elevated HR which remained high as long as the other was displaying during the initial pairings. Although the observing crayfish may not have exhibited bodily movements, its HR still increased. During the physical contact of interaction, HR always rapidly increased. When a pause occurred in a wrestling match, even though the chela may still have been interlocked, HR rapidly decreased. When a pair separates at what appears to be a time of assessing the conflict, the HR either decreases or re- 
mains elevated, independent of whether the animal is the dominant winner or the submissive loser of the recent battle. Dominant and submissive characterizations were used as previously established in social interaction studies of crayfish (Bruski and Dunham, 1987; Huber et al., 1997a,b; Huber and Delago, 1998).

The rapid onset and offset, with minimal duration, of elevated HRs during interactions suggest at least three relatively plausible explanations. Firstly, that HR within a behaving animal is not a good indication of systemic levels of 5-HT. Secondly, that 5-HT levels are not elevated in aggressive individuals either in establishment or maintenance of social status. Thirdly, that possibly the neural command of regulating HR can override systemic excitatory effects of 5-HT on elevation of HR. We performed an initial attempt to examine the effects on HR by induced systemic concentrations of 5-HT from direct injections into the hemolymph. As previously shown by others, 5-HT leads to an overall increase in HR (Florey and Rathmayer, 1978; Harris-Warrick and Kravitz, 1984; Wilkens et al., 1985). Our results indicate that an increase in HR and duration of elevation are associated with 5-HT in a concentration-dependent manner (Table 2). Since the injections produce such prolonged elevations in HR, as compared to both sham injections and to the effects associated with normally interacting crayfish, perhaps the injection procedures used do not mimic systemic alterations in 5-HT levels, even in the neuropile among cardiac regulatory centers. Until a practical method has been devised to monitor 5-HT levels in interacting crustaceans, a definite answer will remain elusive in ascertaining whether 5-HT levels truly rise during aggressive responses. HR measures would appear to be a good bioassay to endogenously released 5-HT, but do not substantiate the finding that $5-\mathrm{HT}$ is elevated during interactions or chronically in aggressive individuals. Further studies are needed to address these issues.

\section{Acknowledgements}

We are grateful for the fruitful conversations with Dr J.L. Wilkens (University of Calgary, Canada) and Dr J. Mercier (Brock University, Ont., Canada). Appreciation is given to Dr Hilary Lambert Hopper for editorial assistance. Illustra- tions were provided by the courtesy of Hye Won Cooper. Appreciation is given to Dr Philip Bonner at the University of Kentucky for the use of microscopy equipment. Funding was provided by a Howard Hughes Medical Institute undergraduate training fellowship (L.R. Listerman), NSFREU (L.R. Listerman), and NSF grants IBN-9808631 and ILI DUE-9850907 (R.L. Cooper).

\section{References}

Alexandrowicz, J.S., 1932. The innervation of the heart of Crustacea. I. Decapoda. Q. J. Micro. Sci. 75, $181-249$.

Alexandrowicz, J.S., 1953. Nervous organs in the pericardial cavity of the decapod Crustacea. J. Mar. Biol. Assoc. UK 31, 563-580.

Aréchiga, H., Garcia, U., Martínez-Millán, L., 1990. Synaptic regulation of neurosecretory cell activity in the crayfish eye stalk. In: Wiese, K., Krenz, W.-D., Tautz, J., Reichert, H., Mulloney, B. (Eds.), Frontiers in Crustacean Neurobiology, Advances in Life Sciences. Birkhäuser, Basle, pp. 373-380.

Bethe, A., 1897. Vergleichende Untersuchungen über die Funktionen des Centralnervensystems der Arthropoden. Pflugers Arch. Physiol. 68, 449-545.

Bruski, C.A., Dunham, D.W., 1987. The importance of vision in agonistic communication of the crayfish Orconectes rusticus, I. An analysis of bout dynamics. Behaviour 63, 83-107.

Cooke, I.M., Sullivan, R.E., 1982. Hormones and neurosecretion. In: Bliss, D.E. (Ed.), The Biology of Crustacean Neurobiology: Structure and Function, vol. 3. Academic Press, New York, pp. 206-290.

Cooper, R.L., Ruffner, M.E., 1998. Depression of synaptic efficacy at intermolt in crayfish neuromuscular junctions by 20-hydroxyecdysone, a molting hormone. J. Neurophysiol. 79, 1931-1941.

Crider, M.E., Cooper, R.L. Importance of stimulation paradigm in determining facilitation and effects of neuromodulation. Brain Res. 842, 324-331.

Delaney, K., Tank, D.W., Zucker, R.S., 1991. Presynaptic calcium and serotonin-mediated enhancement of transmitter release at crayfish neuromuscular junction. J. Neurosci. 11, 2631-2643.

Doshi, D., Li, H., Listerman, L., Cooper, R.L., 1999. Measures of heart rate during social interactions in visual epigean and blind cave crayfish. Am. Zool. 38, 199A.

Evans, P.D., Kravitz, E.A., Talamo, B.R., Wallace, B.G., 1976. The association of octopamine with specific neurons along the lobster nerve trunks. J. Physiol. 262, 51-70. 
Fischer, L., Florey, E., 1982. Modulation of synaptic transmission and excitation-contraction coupling in the opener muscle of the crayfish, Astacus leptodactylus, by 5-hydroxytryptamine and octopamine. J. Exp. Biol. 102, 187-198.

Florey, E., Rathmayer, M., 1978. The effects of octopamine and other amines on the heart and on the neuromuscular transmission in decapod crustaceans: further evidence for a role as a neurohormone. Comp. Biochem. Physiol. 61C, 229-237.

Gleeson, R.A., Zubkoff, P.L., 1977. The determination of hemolymph volume in the blue crab Callinectes sapidus, utilizing ${ }^{14} \mathrm{C}$-thiocyanate. Comp. Biochem. J. Neurosci. 6, 1560-1569.

Glusman, S., Kravitz, E.A., 1982. The action of serotonin on the excitatory nerve terminals in lobster nerve-muscle preparations. J. Physiol. 325, 223-241.

Guirguis, M.S., Wilkens, J.L., 1995. The role of the cardioregulatory nerves in mediating heart rate responses to locomotion, reduced stroke volume and neurohormones in Homarus americanus. Biol. Bull. 188, 179-185.

Grega, D.S., Sherman, R.G., 1975. Responsiveness of neurogenic hearts to octopamine. Comp. Biochem. Physiol. 52C, 5-8.

Harris-Warrick, R.M., Kravitz, E.A., 1984. Cellular mechanisms for modulation of posture by octopamine and serotonin in the lobster. J. Neurosci. 4, 1976-1993.

Huber, R., Delago, A., 1998. Serotonin alters decisions to withdraw in fighting crayfish, Astacus astacus: the motivational concept revisited. J. Comp. Physiol. 182, 573-583.

Huber, R., Orzeszyna, M., Pokorny, N., Kravitz, E.A., 1997a. Biogenic amines and aggression: experimental approaches in crustaceans. Brain Behav. Evol. 50, 60-68.

Huber, R., Smith, K., Delago, A., Isaksson, K., Kravitz, E.A., 1997b. Serotonin and aggressive motivation in crustaceans: altering the decision to retreat. Proc. Natl. Acad. Sci. 94, 5939-5942.

Kravitz, E.A., Glusman, S., Harris-Warrick, R.M., Livingstone, M.S., Schwarz, T., Goy, M.F., 1980. Amines and a peptide as neurohormones in lobsters: actions on neuromuscular preparations and preliminary behavioral studies. J. Exp. Biol. 89, 159-175.

Larimer, J.L., Tindel, L.R., 1966. Sensory modifications of heart rate in crayfish. Anim. Behav. 14, $239-245$.

Lefkowitz, R.J., Hoffman, B.B., Taylor, P., 1990. Neurohumoral transmission: The autonomic and somatic motor nervous systems. In: Gilman, A.G., Rall, T.W., Nies, A.S., Taylor, P. (Eds.), Goodman and Gilman's The Pharmacological Basis of Therapeutics, 8th edn. Pergamon, New York, pp. 84-121.
Li, H., Ward, E., Bradacs, H., Cooper, R.L., 1997. Neuromodulator effects on primary sensory neurons: rapidly and slowly adapting proprioceptors. Abstr. Soc. Neurosci., 313.8.

Listerman, L., Doshi, D., Cooper, R.L., 1999. Measures of heart rate during social interactions and injections of serotonin in visual epigean and blind cave crayfish. East Coast Nerve Net, 25th Annual Meeting, April 9-11 at MBL, Woods Hole, MA.

Livingston, M.S., Harris-Warrick, R.M., Kravitz, E.A., 1980. Serotonin and octopamine produce opposite postures in lobsters. Science 208, 76-79.

McGaw, J., Wilkens, J.L., McMahon, B.R., Airriess, C.N., 1995. Crustacean cardioexcitatory peptides may inhibit the heart in vivo. J. Exp. Biol. 198, 2547-2550.

McMahon, B.R., 1992. Factors controlling the distribution of cardiac output in decapod crustaceans. In: Hill, R.B., Kuwasawa, K., McMahon, B.R., Kuramoto, T. (Eds.), Phylogenic models in functional coupling of the CNS and the cardiovascular system. Comp. Physiol. 11, 51-61.

McMahon, B.R., 1995. Integrated neural and neurohormonal control of respiratory and circulatory function in crustaceans: is there evidence for an 'autonomic' control system? Verh. Dtsch. Zool. Ges. 88 (2), 87-101.

McPhee, M.J., Wilkens, J.L., 1989. Serotonin, but not dopamine or octopamine, modifies locomotor and phototaxic behavior of the crab, Carcinus maenas. Can. J. Zool. 67, 391-393.

Pasztor, V.M., Bush, B.M.H., 1987. Peripheral modulation of mechanosensitivity in primary afferent neurons. Nature 326, 793-795.

Pasztor, V.M., MacMillan, D.L., 1990. The actions of proctolin, octopamine and serotonin on the crustacean proprioceptors show species and neurone specificity. J. Exp. Biol. 152, 485-504.

Vyshedskiy, A., Delaney, K.R., Lin, J.W., 1998. Neuromodulators enhance transmitter release by two separate mechanisms at the inhibitor of crayfish opener muscle. J. Neurosci. 18, 5160-5169.

Wiersma, C.A.G., 1961. Reflexes and the central nervous system. In: Waterman, T.H. (Ed.), The Physiology of Crustacea, vol. II, Sense Organs, Integration, and Behavior. Academic Press, New York, pp. 241-279.

Wilkens, J.L., 1995. Regulation of the cardiovascular system in crayfish. Am. Zool. 35, 37-48.

Wilkens, J.L., 1999. Evolution of the cardiovascular system in Crustacea. Am. Zool. 39, 199-214.

Wilkens, J.L., McMahon, B.R., 1992. Intrinsic properties and extrinsic neurohormonal control of the crab cardiac hemodynamics. Experientia 48, 827-834.

Wilkens, J.L., Mercier, A.J., 1993. Peptidergic modulation of cardiac performance in isolated hearts from 
the shore crab, Carcinus maenas. Physiol. Zool. 66, $237-256$.

Wilkens, J.L., Walker, R.L., 1992. Nervous control of the crayfish cardiac hemodynamics. Comp. Physiol. $11,115-122$.

Wilkens, J.L., Mercier, A.J., Evans, J., 1985. Cardiac and ventilatory responses to stress and to neurohormonal modulators by the shore crab Carcinus maenas. Comp. Biochem. Physiol. 82C, 337-343.

Worden, M.K., 1998. Modulation of vertebrate and invertebrate neuromuscular junctions. Curr. Opin. Neurobiol. 8, 740-745.

Yamagishi, H., Hirose, E., 1997. Transfer of the heart pacemaker during juvenile development in the isopod crustacean Ligia exotica. J. Exp. Biol. 200, 2393-2404.

Yamagishi, H., Ando, H., Makioka, T., 1997. Myogenic heartbeat in the primitive crustacean Triops longicaudatus. Biol. Bull. 193, 350-358.

Yazawa, T., Kuwasawa, K., 1992. Intrinsic and extrinsic neural and neurohumoral control of the decapod heart. Experientia 48, 834-839.

Yeh, S.-R., Fricke, R.A., Edwards, D.H., 1996. The effect of social experience on serotonergic modulation of the escape circuit of crayfish. Science 271, $366-369$. 